\title{
3D Body Scanning Technology for Virtual Design of System "Body-Clothes"
}

\author{
Victor E. KUZMICHEV*1a, Natalia A. SAHAROVA ${ }^{a}$, Gregory I. CHISTOBORODOV ${ }^{a}$ \\ ${ }^{a}$ Ivanovo State Textile Academy, Russia
}

\begin{abstract}
New systematic approach for an analysis and a synthesis of virtual systems "body-clothes" by means of the bodyscanner is developed. All TELMAT' and VITUS possibilities in new information obtaining after the scanning real human bodies and system "body-clothes" were used. Data bases of new method are included several parts, such as (1) a parametric features of basic block pattern (front, back, and one-seam or two-seam sleeves) connected with the human body morphology, (2) a parametric features of modified pattern (square and counter lines configuration) shaping in accordance with the desirable clothes styles, (3) and a textile materials properties measured by special methods. All subjects - patterns, on one hand, and front and profile views, horizontal and vertical cross-sections of system "body-clothes", on other hand, were parameterized. For realistic virtual design of system "body-clothes" a new methods of textile materials testing which allowed to reproduce the real behavior of clothes or their parts are created. New technology based on the new software was applied for designing mass-production clothes (women down jacket and coat, men trousers, women's dresses and blouses).
\end{abstract}

Keywords: 3D body scanning, clothes, shaping, pattern making, textile material

\section{Introduction}

Modern versions of bodyscanners can improve the present CAD and help to create futuristic 3D methods of clothes design in real (ready-to-measure) and virtual ways. Many kinds of bodyscanners, especially produced by TELMAT (France) [1], allow to rich new good results in complex or separately investigations of system "real human body with morphological features - clothes with different outline shapes" or their elements - human bodies, textile materials, clothes surfaces. 3D technologies in clothes design haven't had wide practical application yet, despite the conclusive advantages of virtual design to traditional 2D pattern making. More important reasons which limited the distribution of virtual technologies are absent the ways:

- how to reproduce the pleated real surfaces of single and multilayered virtual clothes,

- how to predict the shape of clothes in system "body-clothes" (later as SBC) in accordance with the patterns features (sizes; eases as a differences between pattern sizes and body dimensions; eases distribution between a front, a back, and an armhole, patterns configurations) and textile materials properties.

So, the main problem is how to connect the flat patterns, the textile materials properties, and $3 \mathrm{D}$ clothing shapes put on the realistic human bodies or manikins. Each subject can be describe by own schedule of indexes which need to connect with others to create the general model of clothes shaping.

A number of scientific researches done in last time in this direction are huge. Nowadays 3D technologies created in 2007-2011 represent the system "body-clothes" in two variants:

1) "skinny" shapes with ideally smooth surfaces located around the human body torso (based on the Chebishev's theory). Such method of clothes shaping is used, for example, for underwear design. J.Siegmund, S.Krzywinski, H.Rodel [2] find the way is based on the drafting the women's bra directly on the virtual manikin. The pattern parts developed on 3D body shape, then ones transform into $2 \mathrm{D}$ patterns by means of innovative software by wrapping flat. H.Huang, P.Y/Mok, Y.L.Kwok, J.S.Au [3] the proposed method can generate 2D block patterns from 3D unstructured point cloud represented by scanned human body. In this investigation the relationship between the human body dimensions, patterns sizes and darts values are investigated, and finally the pattern creation done through automatic dart transformation;

2) "loose" shapes having the air gaps located between the human body and the clothes on the anthropometric levels. By means of the air gaps the single-layer clothes as much as possible may be shaped around the human body. A. Cichocka, P.Bruniaux, V.Koncar [4] created the fundamental model of trousers design in 3D that composed of three parts - a human body model, an air ease

\footnotetext{
1* wkd37@list.ru; +7-4932-357881; www.igta.ru
} 
(gaps) model between the body and trousers and a trousers pattern generated from virtual system "body-trousers". This way in 3D design is more convenient because includes all important parts of clothes shaping and allows to connect the body and the pattern across the air gaps. H.Q. Hung, P.Y.Mok, Y.L.Kwok, J.S.Au [5] tried to fit the clothes on the bearing surface of human body in right position used the triangulated body and clothes mesh models for the determination the main points to draw the neckline.

In both variants the textile materials presenting in mathematical models as an important element of clothes shaping haven't strong correlation with real features which real clothes shown on the human body. As usual

the shaping process is different for clothes with very small, small and big volume. So, each shape of clothes needs own schedule of textile materials properties that responsible for forming and draping on the upper and down parts.

The next independent way of bodyscanners using is to design a ready-to-measure and to virtualize the new system. For example, S. Petrac, M. Mahnic, D. Rogale, D. Ujevic [6] find the way of designing of women's cocktail dresses in according with the style, patterns and morphological features of body to take an attention for anthropometric characteristics of the body and know how specific pattern modification. They put into the software how to apply the dress patterns with appropriate look of body figure.

Thus, to increase the realness of interaction between the human body and the clothes it's necessary to use the mathematical description which includes the textile materials properties. However it is not enough to get the realistic shape of virtual clothes. In our opinion, to improve the 3D clothes virtual design is important to formalize all relationships that consist between the similar parts of three independent subjects: (1) the block pattern, (2) the human body, (3) the clothes shapes, and (4) the textile materials which used to do the patterns. Really practicing designers have such knowledge how to fit the patterns on the body, and the problem is how to formalize it ideas for computer design. New up-to-data information should connect the sizes of the different areas of clothes by equations, for example, on the waist, bust, hip levels, if one of them is changed.

\section{Method used}

Department of Garment Design (Ivanovo State Textile Academy, Ivanovo, Russia) with College of Apparel Design (Wuhan Textile University, Wuhan, Hubei, PRC) has been doing the complex research about how to use the bodyscanners for studying the 3D clothes shaping under the influence of special conditions, such as 2D block patterns and different textile materials. In our investigation we used the next devises, software, and methods:

- bodyscanners - white light TELMAT Optifit Pro-2 (France) with two camera Toshiba; laser VITUS Smart 3-D (Vitrinic) with software ScanWorX (version 2.9) and Anthroscan (version 2.9),

- software - ImageWare, own products,

- methods - new tests for describing the textile materials behavior in 3D especially when its samples put on the human body as a real clothes,

- kinds of clothes - women down jacket, trousers, dress, blouse, coat.

\section{Results}

There are seven directions of possible ways which we could use a bodyscanner for improving the clothes design and connecting the different steps in virtual design, such as:

1. Creating the new data base about morphological structure of human body and the clothes covering ones.

2. Reconstruction the body and clothes surfaces after scanning.

3. Improving the traditional 2D pattern design.

4. Reconstruction of clothes pattern after complex analysis real system "body-clothes" scanning before.

5. 3D design of clothes shapes with realistic surfaces for typical and untypical bodies.

6. Recognition the features of system "body - clothes".

7. Creation the new methods of textile materials testing.

In the next part of article we put our main results which we have got during our four-year research.

\subsection{Complex databases about human bodies and systems "body - clothes"}

New databases obtained are including next results about the 3D bodies and 3D clothes:

- body dimensions (circumferences, lengths, widths, heights, distances) measured between different anthropometric points on the body' surface, on one hand, and different horizontal levels, on other 
hand, in according with the choosing anthropometric program. It's easy to increase the dimensions in the schedule if you know how to use ones in (1) pattern making process, (2) real or virtual manikin' (dummy') construction, or (3) 3D systems "body - clothes". For example, we have obtained some new body dimensions for improving all subjects mentioned;

- clothes dimensions measured on its surfaces. We extend the possibilities of TELMAT by means of including the clothes in the schedule of scanning objects. To get the good results after scanning, all objects (bodies, clothes) need to have the special features (for example, black materials did impossible to measure the point coordinates on the surfaces). More exact results after measuring we could get if the clothes have the morphological structure (or) a shape as the human bodies. It's useful when the clothes have a similar seams as a natural lines belonging to a body (for example, as a lines between a torso and an upper arm, between a torso and a neck, narrow area on the waist level). After scanning a system "body - clothes" we could get the same list of a measurements as after scanning a body;

- air gapes (or air eases) in system "body - clothes" which located between a body and a clothes. To calculate the air gapes values, we have created the special software to get the cross-sections on the different anthropometric levels (bust, waist, hip, knee, etc). Each object after scanning - a body and clothes - has the vertical axe across the weight center. Due to that axes two cross-sections - the one from body and the second from the clothes - could compare and measure for parametrization of air gapes. Figure 1 shown the example of cross-sections obtained after connecting two cross-sections belonging to a body and dress on the same anthropometric levels. For connecting the cross-sections we used ImageWare software.

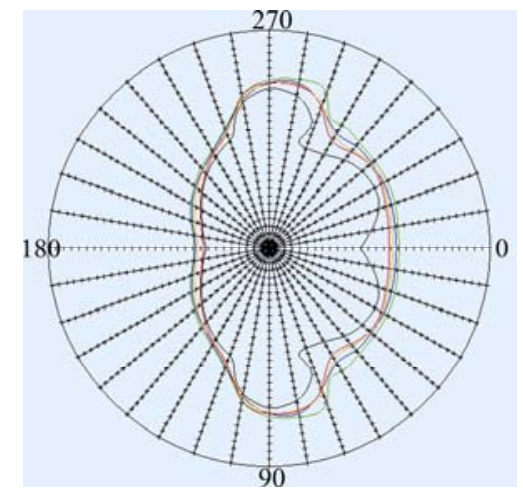

a.

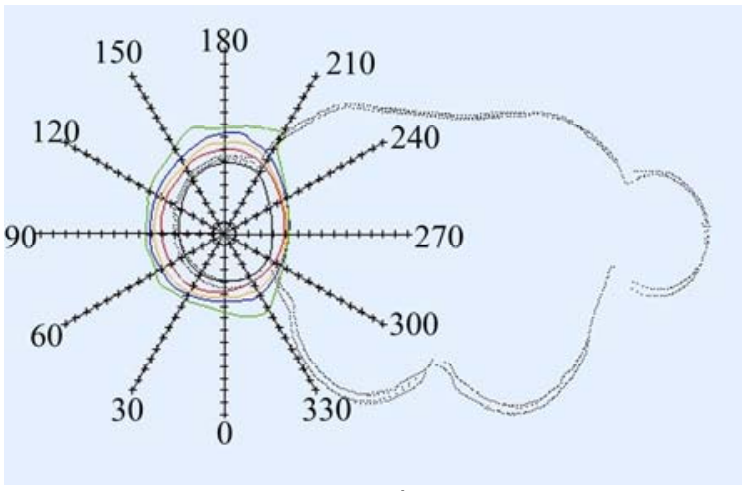

b.

Fig.1. Cross-sections belonging to the scanning system "women body - dress" made on the bust girth level (a) and the arm girth level (b). Pictures $a, b$ shown the method of dividing the cross-sections into small parts to measure the air gape values around a body and an arm.

So if we know how the air gape values in system "body-clothes" are changing, we can describe the different shapes more exactly and express each outline shape by means of numerical way.

\subsection{Reconstruction the body and clothes surfaces after scanning}

As has been established on the basis of the analysis to scanning systems, the scanning technology by means of white light has a problem about invisible areas for scanning dead angle sites of figures. The reason of occurrence invisible for scanning dead angle areas are their arrangement under the corner to an external surface of a torso, hands, legs and inaccessibility of internal surfaces (between hands and torso, between legs, under arms) and lateral surfaces (figure 2, a). We have developed intellectual technology of elimination of not scanning sites. Process of transformation of the information occurred under the circuit: a real figure $\rightarrow$ a virtual figure $\rightarrow$ the integrated complete virtual figure. Bodyscanner TELMAT generates scanning files of type ( ${ }^{*}$.sacq) and ( ${ }^{*}$.iv): the first type of a file is created specially for TELMAT, and the second type is a popular file, and it can be open in anyone CAD. The developed program automatically compares all points according to the initial order. All points which laying around holes, are restored and formed in the separate module with simultaneous registration of serial numbers of these points. Therefore after reconstruction, all points can be put on the initial places (figure 2, $b$ ).

\subsection{Improving the traditional 2D pattern design}

In our opinion the new ways for improving the traditional 2D pattern making by means of bodyscanners are: 
- import of new body dimensions for pattern making to get more fitting and comfortable clothes, especially for different types of bodies (European, Asian);

- creating the new combination of body dimensions for the pattern checking (front, sleeve, back) created for bodies with morphological features. Next important values could be checking in each pattern: (1) the balances in horizontal, slope and vertical directions responsible for clothes good and bad fitting, (2) the eases values (ease is a difference between the body size and appropriate pattern size, for example, between a half bust girth and a block width). There are main eases to bust girth and its parts in front width, back width and armhole width, to hip girth, to arm girth, to tight girth, and others, (3) and sizes of pattern in static and dynamic positions in according of textile materials flexibility and human body posters;

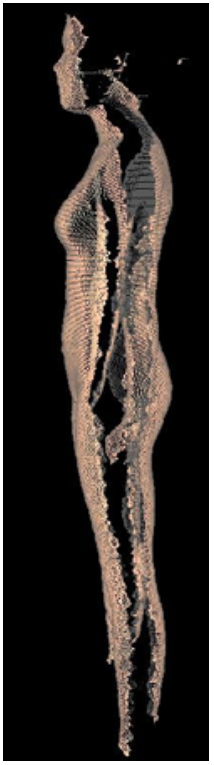

a.

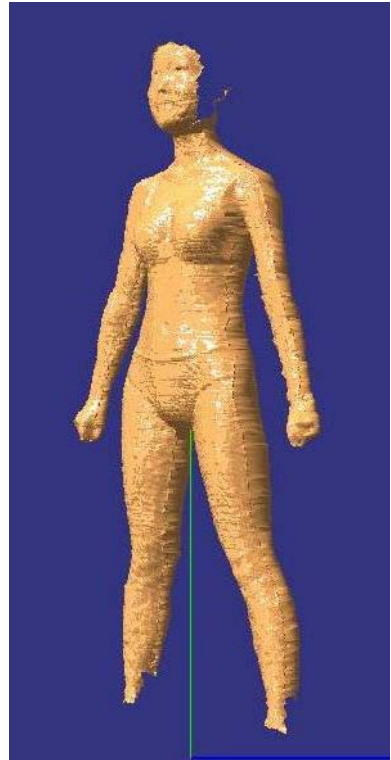

$b$.

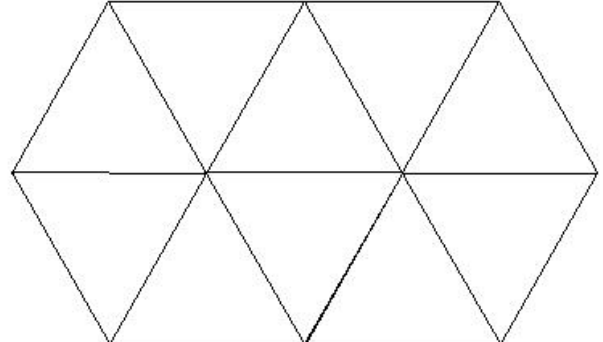

C.

Fig. 2. Appearance of a virtual bodies: a - real body after scanning by TELMAT with not looked areas (in black), $b$ - the integrated complete virtual body after the reconstruction, $c$ - small sites, integrated at the reconstructing surfaces

- new knowledge about the complex influence of different eases which taken place in real shaping of $3 \mathrm{D}$ clothes.

We find the main places on the clothes surfaces which had the strong influence by main eases from the basic and modified patterns. If we want to create the new outline shape by means of the eases combination during the pattern making process we need know the final results of its common action. Figure 3 shown the more informative places which can use as the indicators of clothes shapes and common influence of different eases combination. If we will increase the eases values during the pattern making, we can to rule the outline shapes especially in such areas which marked in grey.

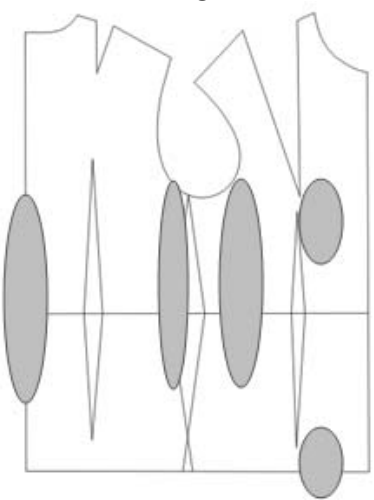

a.

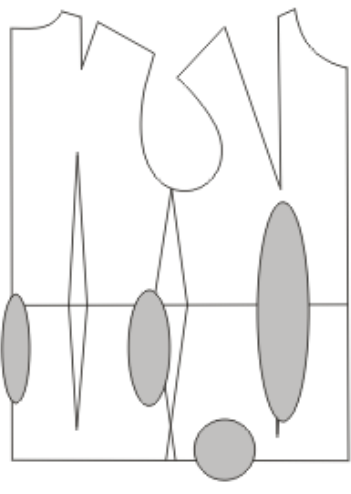

$b$.

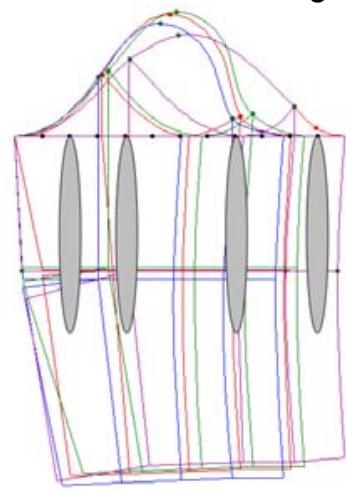

C.

Fig. 3. Schemes of patterns block (a - block of women classical suit, $b$ - block of women coat, $c$ - block of oneseam sleeve) with more informative areas (mark in grey) under which the air gaps are changed more strong when main eases are increasing 
If we will increase the eases values during the pattern making, we can to rule the outline shapes especially in the areas which marked in grey. We established the main rules of outline shape changing by means of main eases in block pattern (eases to bust girth, waist girt, hip girth, back width, armhole depth, etc.). The next row shown the influence in order of weakness: ease to bust girth - ease to armhole width - ease to back width - ease to front width - ease to hip girth - ease to waist girth. So an eases are the main way to predict the outline shape of clothes.

\subsection{Clothes pattern reconstruction after complex analyze scanning real system "body - clothes"}

Using new databases formed after scanning bodies and SBC (air gapes values, lengths of cross section' contours in vertical and horizontal directions, wrinkle depths, etc.) we could calculate the pattern parameters (front, back, and sleeve width and length) for the block reconstruction. By this way we could transform the indexes belonging to $3 \mathrm{D}$ clothes with non simple shape (such as dress, jackets, trousers, etc.) into the indexes of flat $2 \mathrm{D}$ pattern.

The research is directed on working out of methodology of new design of clothes in system "CAD + 3D body scanner". Two new databases are put in a basis of this methodology: the first one includes the schedule of indexes about the patterns (2D), collected from second half $X X-X X I$; the second one includes the quantity information about the outline clothes shapes (3D) of the same period, digitized by the bodyscanner. The new technology that connecting the flat patterns (front, back, sleeve), on one hand, and the outline shapes of systems "body-clothes", on other hand, is developed for main kinds of outer clothes (jackets, coats, dresses, trousers).

Figure 4 shown the real scanned SBC and the trousers patters reconstructed after complex analyzing of SBC.

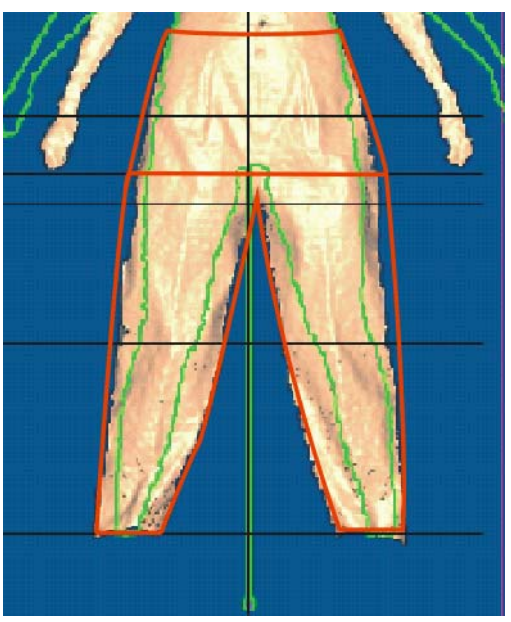

a.

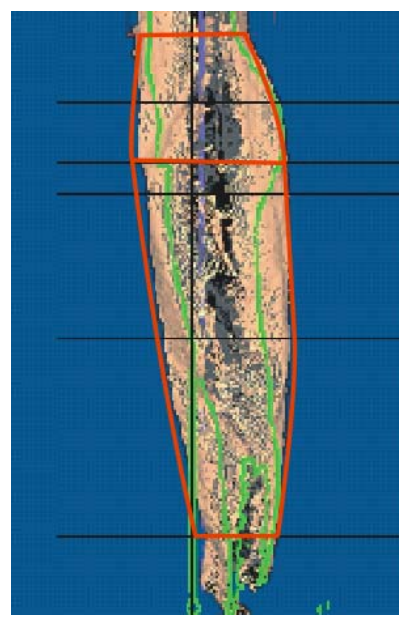

$b$.

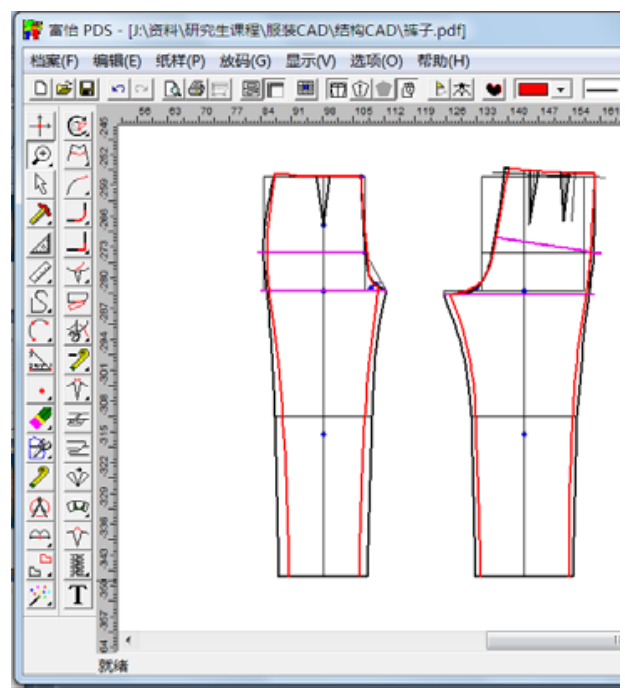

c.

Fig. 4. Scanned SBC in front (a) and profile (b) views (outline approximate line belongs to the trousers obtained from reconstructed patterns) and the trousers patters (c) reconstructed after complex analyze SBC by means of own software

\subsection{D design of clothes shapes with realistic surfaces for typical and untypical bodies} In our opinion the weakest position of modern 3D CAD design is ignorance the clothes patterns influencing for the 3D features. In this direction we did some works which include:

(1) new classifications of 3D clothes shapes based on the usual features of shape (such as closely fitting, loosely fitting, semi closely fitting, etc), on one hand, and the air gapes in system "body clothes", on other hand. This classification allows to connect the 3D shape and 2D patterns and to predict the clothes shaping. As example you can see the fragment of such classification that we created for women clothes (table 1). Sections positions shown in figure 1, a. 
Table 1. Fragment of new classification connecting an eases values in $2 D$ block patterns and an air gapes in system "body - clothes" (for women body 164- 88 - 96 and dresses)

\begin{tabular}{|c|c|c|c|c|c|c|}
\hline \multirow{2}{*}{$\begin{array}{l}\text { Kinds of } \\
\text { clothes } \\
\text { shape in } \\
\text { front view }\end{array}$} & \multicolumn{3}{|c|}{ Pattern eases, $\mathrm{cm}$} & \multicolumn{3}{|c|}{$\begin{array}{l}\text { Air gape in system "body - clothes", cm, in } \\
\text { different sections on the bust/hip/waist } \\
\text { levels, degree }\end{array}$} \\
\hline & $\begin{array}{l}\text { ease to half } \\
\text { bust girth }\end{array}$ & $\begin{array}{l}\text { ease to half } \\
\text { hip girth }\end{array}$ & $\begin{array}{l}\text { ease to half } \\
\text { waist girth }\end{array}$ & front, $0 \ldots 70$ & $\begin{array}{l}\text { under } \\
\text { armhole, } \\
70 \ldots 120\end{array}$ & $\begin{array}{c}\text { back, } \\
120 \ldots 180\end{array}$ \\
\hline $\begin{array}{l}\text { Very closely } \\
\text { fitting }\end{array}$ & $1,8 \ldots 3$ & $2,5 \ldots 4$ & $2,5 \ldots 4$ & $\frac{0,3 \ldots 1,6}{0,2 \ldots 1,2}$ & $\frac{0,2 \ldots 1,4}{0,5 \ldots 1,6}$ & $\frac{0,2 \ldots 0,9}{1,1 \ldots 2,3}$ \\
\hline $\begin{array}{l}\text { Closely } \\
\text { fitting }\end{array}$ & $3 \ldots 5$ & $4 \ldots 7$ & $4 \ldots 7$ & $\frac{1,6 \ldots 2,9}{\frac{1,2 \ldots 2,2}{1,9 \ldots 3,7}}$ & $\frac{1,4 \ldots 2,7}{\frac{1,6 \ldots 2,7}{0,4 \ldots 0,6}}$ & $\frac{0,9 \ldots 1,5}{2,3 \ldots 3,5}$ \\
\hline $\begin{array}{l}\text { Semi } \\
\text { closely } \\
\text { fitting }\end{array}$ & $6 \ldots 10$ & $7 \ldots 11$ & $7 \ldots 8$ & $\begin{array}{l}\frac{2,9 \ldots 4,1}{2,2 \ldots 3,2} \\
3,7 \ldots 5,5\end{array}$ & $\frac{2,7 \ldots 4}{2,7 \ldots 3,8}$ & $\frac{1,5 \ldots 2,2}{3,5 \ldots 4,7}$ \\
\hline $\begin{array}{l}\text { Loosely } \\
\text { fitting }\end{array}$ & $10 \ldots 14$ & $11 \ldots 14$ & $8 \ldots 10$ & $\frac{4,1 \ldots 5,4}{\frac{3,2 \ldots 4,3}{5,5 \ldots 7,3}}$ & $\frac{4 \ldots 5,4}{\frac{3,8 \ldots 5,1}{0,8 \ldots 1}}$ & $\frac{2,2 \ldots 2,9}{\frac{4,7 \ldots 6}{0,7 \ldots 0,9}}$ \\
\hline
\end{tabular}

The nest example shown how to use the new classification.

1. Choose from table 1 the desirable dress style, for example, closely fitting.

2. To reach this silhouette in front view the patterns - front and back - should done with the next eases (from second row): to half bust girth $-3 \ldots 5 \mathrm{~cm}$, to half hip girt $-4 \ldots 7 \mathrm{~cm}$, to half waist girth $4 \ldots 7 \mathrm{~cm}$. The smallest eases are used for the thin textile materials, the biggest ones - for thick materials.

3. Then it's possible to draw the curved lines around the virtual manikin belonging to clothes shape on the bust, waist, and hip levels. Distances between two subjects or air gaps between the manikin and the clothes on the bust level are: on the front $-1,6 \ldots 2,9 \mathrm{~cm}$, under the armhole $-1,4 \ldots 2,7 \mathrm{~cm}$, on the back $-0,9 \ldots 1,5 \mathrm{~cm}$. Then we could find the air gaps on the hip and waist levels. Using these values we can to build the structure (frame) of desirable 3D SBC.

Table 2 includes the equations for calculation of air gap after the patterns drawing automatically.

Table 2 includes the equations to calculate the air gap by means of eases value which used in pattern making.

Table 2. Equations for predict the air gap values $A G$ between the body and women classical suit

\begin{tabular}{|c|c|c|c|}
\hline $\begin{array}{l}\text { Vertical } \\
\text { section, } \\
\text { degree }\end{array}$ & $\begin{array}{c}\text { Anthropometrical } \\
\text { level }\end{array}$ & Equation & $\begin{array}{c}\text { Interval of air gap } \\
A G, \mathrm{~cm}\end{array}$ \\
\hline \multirow[t]{3}{*}{0} & bust & $A G=-0,4 \Pi_{\text {Сг3 }}-1,1 \Pi_{\mathrm{C} \sigma}+0,7 \Pi_{ш П р}+4,3$ & $2,4 \ldots 5,4$ \\
\hline & waist & $A G=0,1 \Pi_{\mathrm{Cr} 3}+0,2 \Pi_{\mathrm{C} \sigma}-0,1 \Pi_{ш \Pi \mathrm{p}}+0,9$ & $1,4 \ldots 3,4$ \\
\hline & hip & $A G=0,8 \Pi_{\mathrm{Cr} 3}-0,1 \Pi_{\mathrm{C} \sigma}+0,5 \Pi_{ш \Pi p}+4$ & $3,9 \ldots 7$ \\
\hline \multirow[t]{3}{*}{40} & bust & $A G=0.1 \Pi_{\mathrm{Cr} 3}+0,1 \Pi_{\mathrm{C} \sigma}+1,3$ & $1 \ldots 2,4$ \\
\hline & waist & $A G=0,1 \Pi_{\mathrm{C}\ulcorner 3}+0,2 \Pi_{\mathrm{C} \sigma}+0,9$ & $3 \ldots 5$ \\
\hline & hip & $A G=0,3 \Pi_{\mathrm{C}\ulcorner 3}+0,2 \Pi_{\mathrm{C} \sigma}+2,9$ & $3,7 \ldots 7,4$ \\
\hline \multirow[t]{3}{*}{70} & bust & $A G=-0,5 \Pi_{\mathrm{C} r 3}+0,4 \Pi_{\mathrm{C} \sigma}+4,6$ & $2,4 \ldots 7,5$ \\
\hline & waist & $A G=0,1 \Pi_{\mathrm{C} r 3}+0,3 \Pi_{\mathrm{C} 6}+1,6$ & $2,5 \ldots 5,5$ \\
\hline & hip & $A G=0,1 \Pi_{\mathrm{C} r 3}+0,02 \Pi_{\mathrm{C} 6}+1,5$ & $1,5 \ldots 3$ \\
\hline \multirow[t]{3}{*}{120} & bust & $A G=-0.03 \Pi_{\mathrm{Cr} 3}-0,1 \Pi_{\mathrm{C \sigma}}+0,4 \Pi_{\text {шПр }}+0,7$ & $0,5 \ldots 2,2$ \\
\hline & waist & $A G=-0,3 \Pi_{\text {Сг } 3}+0,5 \Pi_{\text {С } 6}+1,4 \Pi_{ш \Pi p}+0,8$ & $1,6 \ldots 7,7$ \\
\hline & hip & $A G=0,03 \Pi_{\mathrm{Cr} 3}-0,1 \Pi_{\mathrm{C} \sigma}+0,6 \Pi_{ш П \mathrm{p}}+0,9$ & $0,8 \ldots 2,5$ \\
\hline \multirow[t]{3}{*}{180} & bust & $A G=-0,3 \Pi_{\mathrm{Cг} 3}+0,04 \Pi_{\mathrm{CT}}+0,8 \Pi_{ш \Pi p}+1$ & $0,3 \ldots 1,2$ \\
\hline & waist & $A G=-0,04 \Pi_{\text {Сг3 }}-0,6 \Pi_{\text {Ст }}+2,1 \Pi_{ш П р}+7,9$ & $2,7 \ldots 5,5$ \\
\hline & hip & $A G=-0,2 \Pi_{\mathrm{Cr} 3}-0,2 \Pi_{\mathrm{CT}}+1,6 \Pi_{Ш \Pi p}+3,1$ & $1 \ldots 3$ \\
\hline
\end{tabular}

Notes. 1. $\Pi_{\mathrm{Cr} 3}$ - ease in the pattern to the body dimension "Half bust girth", $\Pi_{\mathrm{C} T}$ - ease in the pattern to the body dimension "Half waist girth", $\Pi_{\mathrm{C} \sigma}$ - ease in the pattern to the body dimension "Half hip girth", $\Pi_{ш п р}$ - ease in the pattern to the armhole width. 2. Scheme of $A G$ measurements shown in figure 6. 
Results in table 2 open the new way of connection between the flat pattern, on the one hand, and 3D clothes shape obtained from these patterns, on the other hand. Using the equations from table 2 we can calculate the air gaps in more important areas;

(2) creation of the typical cross sections of SBC with different outline shapes. Figure 5 shown the typical cross sections of women classical suits on the bust, waist and hip levels.

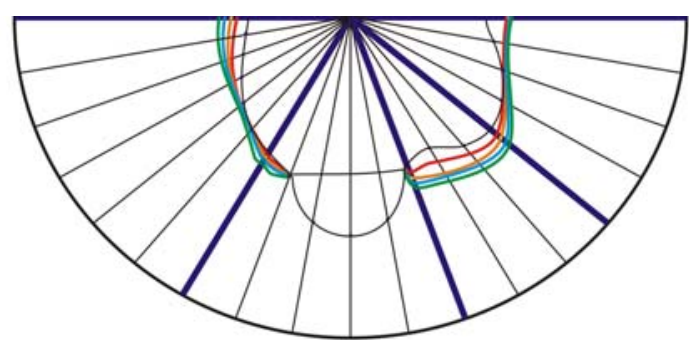

Bust level

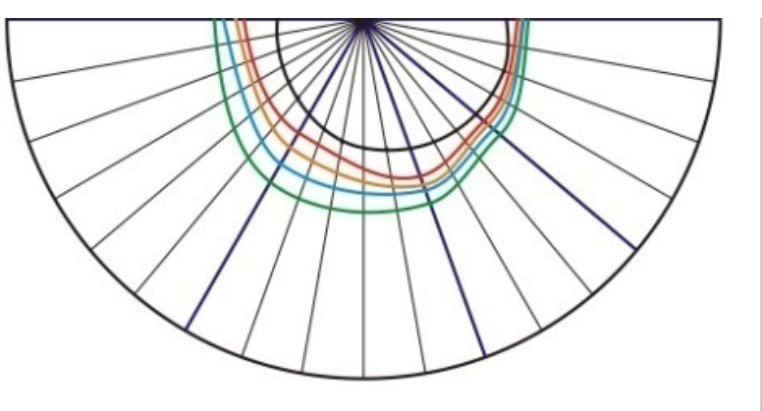

Waist level

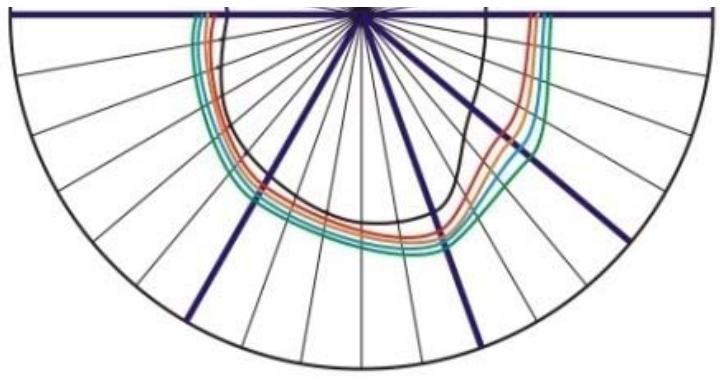

Hip level

a.

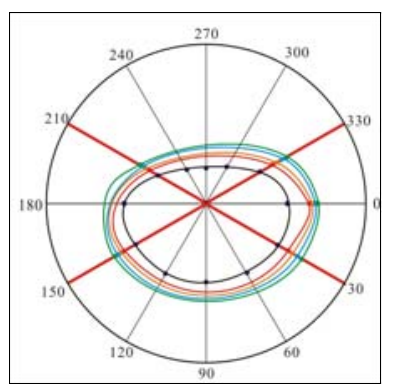

Level of armpit back level

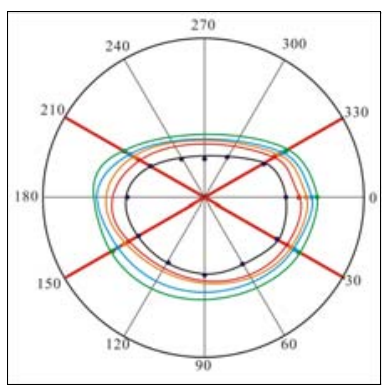

Bust level

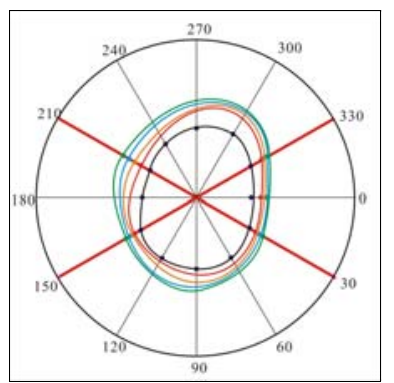

Elbow level

$b$.

Fig. 5. Theoretical cross sections of system "women body - classical suit" with different shapes (very closely, closely, semi closely, loosely sections are located in the same order from the body) on the different levels:

$$
a \text { - front + back, } b \text { - sleeve }
$$

3) creation the frame of designing system "body - clothes" from horizontal and vertical cross sections that crossed in more important and informative points. Systems of the equations, uniting both databases and allowing direct of indexes belonging to the clothes outline shape are generated. Relationships for prognozing the values of shapes and silhouettes of SBC under the influence of pattern indexes (eases equal to differences between the pattern sizes and body dimensions, configuration of counter lines, position of darts, etc.) are received. Informative areas of main kinds of clothes and the equations for their changing are defined.

Figure 6 shown the theoretical frame of women jacket calculated by systems of equations. 


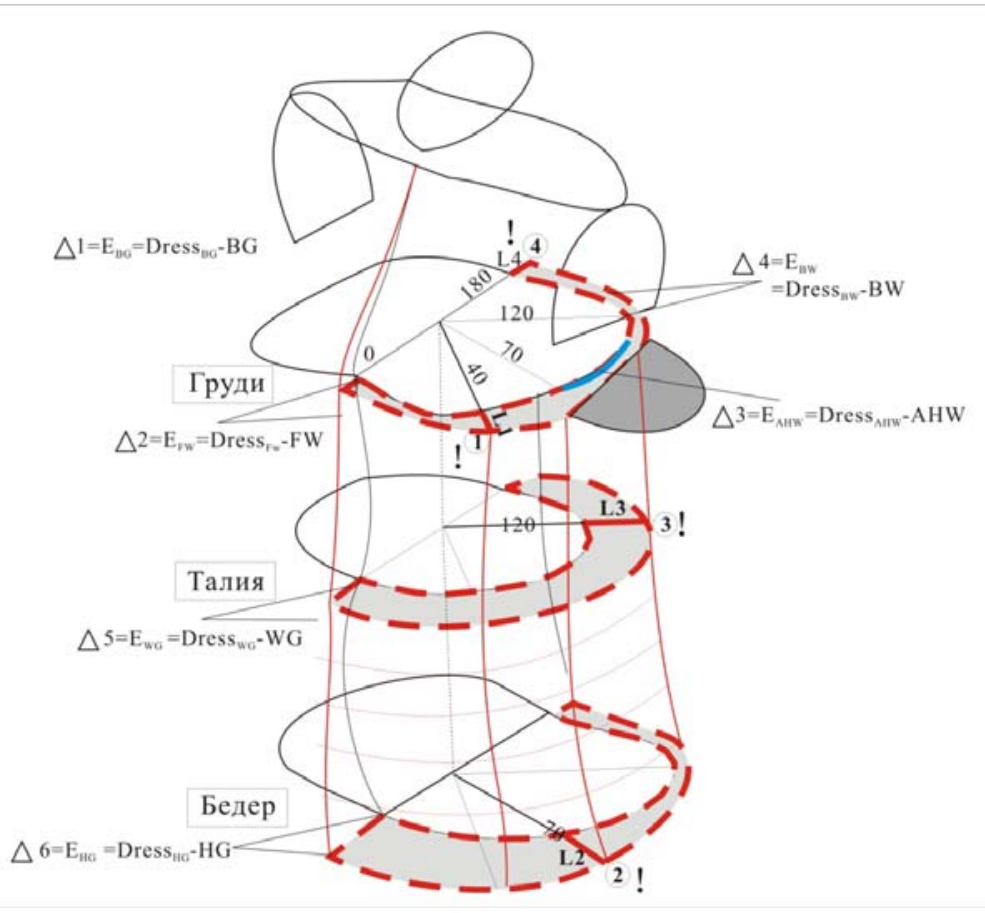

a.

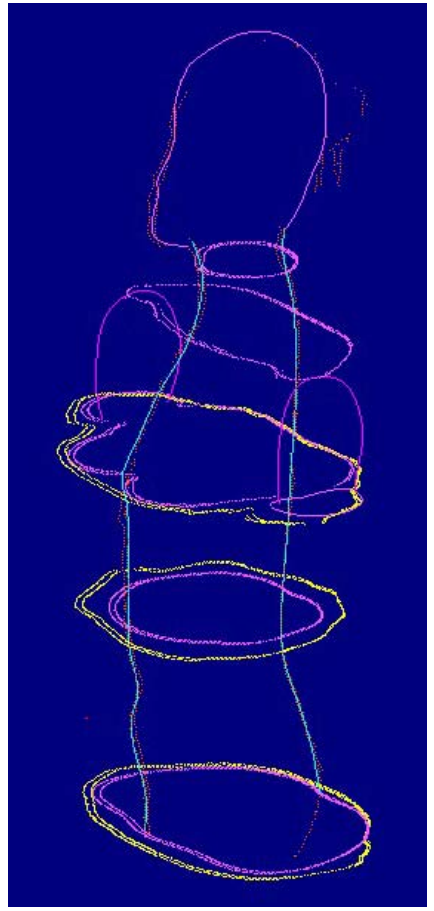

6.

Fig. 6. Theoretical frame of 3D system "women body - jacket" preparing for putting of textile material (a) and virtual model of real system (б)

\subsection{Recognition the features of system "body - clothes"}

To recognize the system "body - clothes" we must have the complex databases which include horizontal and vertical cross sections, features of surface structure, wrinkle shapes, etc. To recognize the scanning clothes we need to compare ones with the before grouped similar objects which have the known complex indexes. The results of recognition are:

- belong or not belong the clothes shape to the known kinds of simplest shapes (closely fitting, loosely fitting, etc.). Identification of the checking shape could be did after calculation and comparison their single air gapes on the main anthropometrical levels situated under certain areas with the same indexes of typical shapes. It's possible to use the complex index such as the full air volume between the body and clothes. In both ways of identification the special teaching access must be created; - belong or not belong the clothes shape to the known kinds of more complex shape (for example, old-fashionable shapes from 1950s, 1960s, 1970s, 1980s, 1990s, etc.). By this way the silhouette lines belonging to front and profile views (front, back, side) - their configuration and quantity indexes for it describing - are analyzed. The teaching access must include the catalogue of typical silhouette lines grouped in accordance with the type of shapes. Figure 7 shown the united front and profile silhouette lines of women dresses and the intervals for outlines in women classical suits which were made in different fashion periods.

Silhouette lines from the obtaining catalogue should be taken to compare with the checking shape and to make a decision about the possible time when this shape may be created. Figure 4 also shown the way how to compare the silhouette lines from the catalogue with the real scanning trousers.

\subsection{Creation the new methods of textile materials testing}

Textile materials have the special features which depend from the conditions of its using. In our opinion the traditional methods of testing such as in Kawabata system are not available for 3D design because the conditions during testing and during the forming SBC are different. Clothes have some areas contacting with a body and shaping in different conditions as a result of unequal forces influence. So to describe the behaviour all parts of clothes by means of only one textile materials test method is impossible.

The best way of sample testing is to reproduce or approximate the conditions and forces have being between the body and clothes to the testing conditions. Results obtained in these tests can be used directly in mathematical description of simulation and modeling of virtual SBC. 


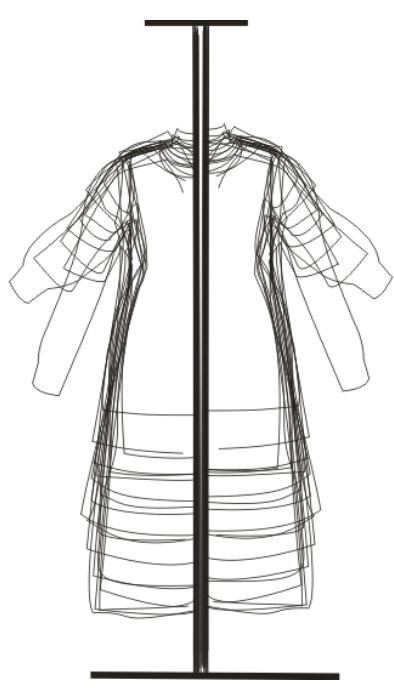

a.

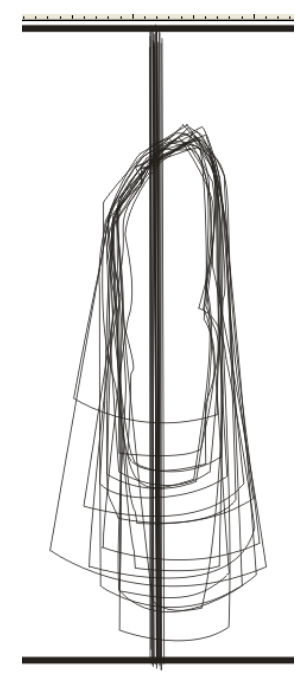

$b$.

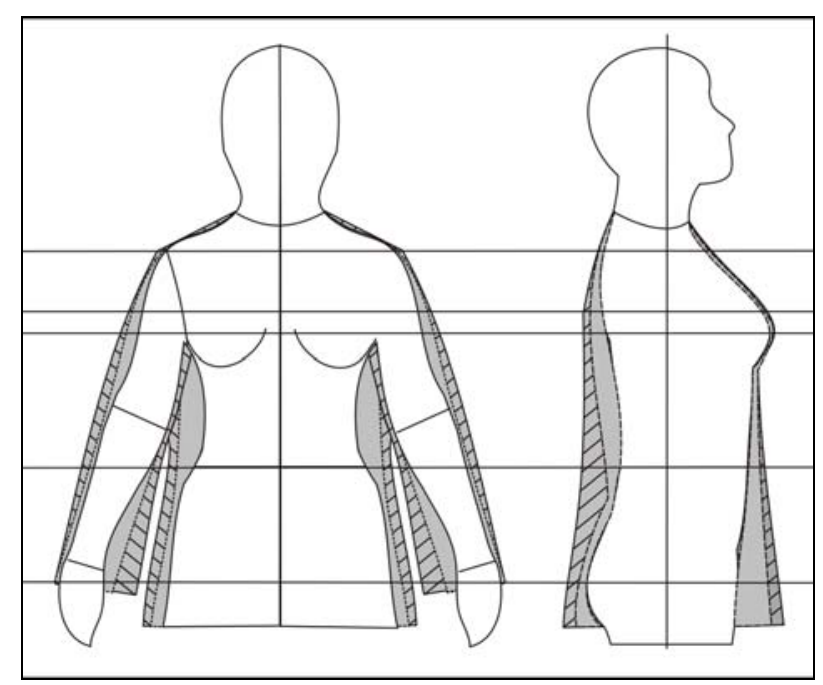

C.

Fig. 7. Typical silhouette lines of women dresses from 1950s, 1960s, 1970s, 1980s, 1990s (a, b) and possible air gaps and intervals for outlines in women classical suits (c)

Figure 8 shown some new methods of textile materials testing created under the influence of real clothes and its parts shaping. Figure $8, a, b$ shown the forming of real collar and corresponding test method of which repeated the scheme of textile materials deformation. Figure $8, c, d$ shown the profile view of SBC and corresponding test method of simulation of sample draping located on the bearing body upper area.
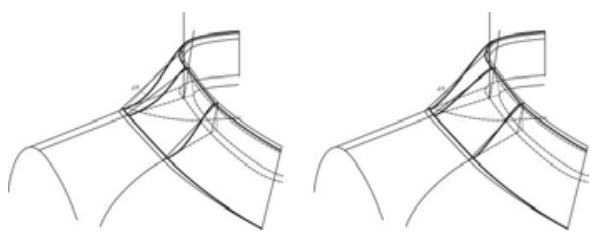

a.

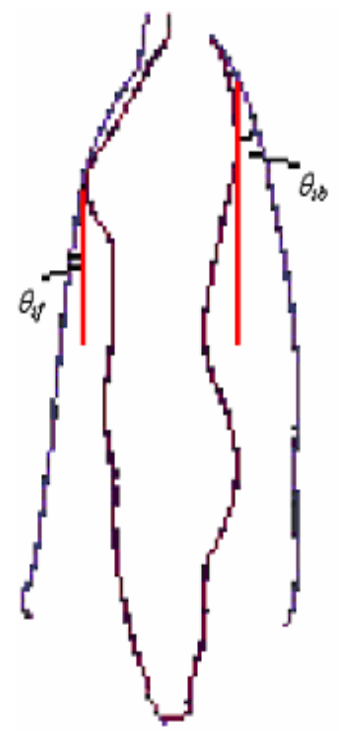

c.

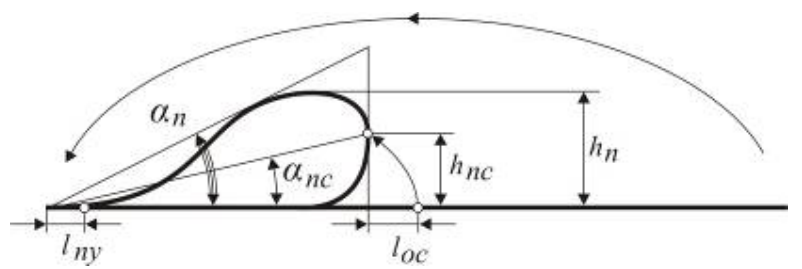

b.

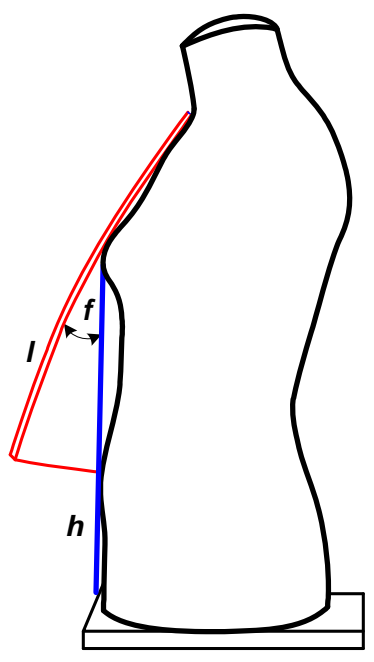

d.

Fig. 8: Real shaping of collar (a) and women down jacket in scanned SBC (c) and corresponding them both schemes of sample testing to predict the collar shape (b) and jacket shape (d). 
The results of both tests have the very strong correlation with the real clothes features and so can be used in general mathematical model in virtual 3D design. So the full model of clothes shaping need include several indexes of textile materials properties.

\section{Conclusion}

Thus, this article is the attempt to systemize the results obtained during our four-year research about $3 D$ shaping of clothes and looking for new ways how to improve the traditional 2D process of pattern making and connect 2D and 3D. Both directions are based on the new information received by means of the bodyscanners which allow investigating the shapes of human bodies and shapes of clothes did from different textile materials. Bodyscanners can increase the speed of real system "body-clothes" investigations and open the new way of pattern making.

\section{Acknowledgments}

Authors would like to thank all colleagues which done with them together all experiments (Li Yue, Luo Yun, N.M.Kochanova, N.V.Afanasyeva).

\section{References}

1. Rennesson, J-L., (2007): "Symcad High Speed 3D Sensors Used in a Military Environment", Proceeding of $5^{\text {th }}$ International Conference Innovation and modeling of Clothing Engineering Processes (IMCEP 2007), Maravske Toplice, Slovenia, pp.116-124.

2. Siegmund, J., Krzywinski, S. and Rodel, H., (2007): "Development of Virtual Parametric Female Bodies for 3D Design of Tight Fitting Garments", Proceeding $5^{\text {th }}$ International Conference Innovation and modeling of Clothing Engineering Processes (IMCEP 2007), Maravske Toplice, Slovenia, pp.125-130.

3. Huang, H., Mok P.Y., Kwok Y.L., Au J.S., (2010): "Automatic Block Pattern Generation from 3d Unstructured Point Cloud”, Research Journal of Textile and Apparel, vol. 14, No. 1, pp. 2637.

4. Cichocka, A., Bruniaux, P., Koncar, V., (2007): "Modelling of Virtual Garment Design in 3D", Research Journal of Textile and Apparel, Vol. 11, No.4, pp. 55-63.

5. Huang, H.Q., Mok P.Y., Kwok Y.L., Au J.S., (2011): "Determination of 3D necklines from scanned human bodies", Textile Research Journal, Vol. 81, No. 7, pp.746-756.

6. Petrak, S., Mahnic, M., Rogale, D., Ujevic, D., (2011): "Computer Design of Textile and Clothing Collection - Assumption of Contemporary Remote Business", Proceeding of AUTEX 2011 Conference: 150 Years of Innovation and Research in Textile Science, 2011, Mulhouse, France, pp.1162-1168. 